\title{
HEALED MICROSCOPIC FOCI OF TUBERCULOSIS IN THE KIDNEY
}

\author{
By DAVID BAND, F.R.C.S.E. \\ (Senior Assistant Surgeon, Western General Hospital, Edinburgh, Associate in Urology, \\ Roval Infirmary, Edinburgh)
}

\section{Introduction}

It is orthodox teaching that healing does not occur in renal tuberculosis. This dictum was rightly reaffirmed by Cabot (I933), but in the same article he qualified it by reminding clinicians that renal tuberculosis, as they viewed the disease, was an open lesion. It is necessary, therefore, to look back to the etiology of renal tuberculosis in order that the pathogenesis of the lesions in the kidney may be followed up. There is no greater fundamental principle in the consideration of the disease than that tuberculosis is a generalised infection with focal manifestations. In the invasive stage tubercle bacilli infect the lymphatic system. An entrance is gained through the tonsils and the glands in the neck, or through the lungs and the peribronchial lymphatics, or through the intestine and the intestinal villi. The bacilli are airborne or ingested. Once the lymphadenoid tissues have been invaded successfully the centripetal flow of infected lymph carries the organism to the blood stream via the great lymphatic trunks (Munro, I94I). In this manner implantations of tubercle bacilli reach the viscera, the serous surfaces, the bones and joints from the blood stream. Their release may be dramatic and overwhelming, as in miliary tuberculosis or tuberculous meningitis; on the other hand, it may be elusive and insidious as in early visceral tuberculosis of the lung or alimentary tract. Whether the implantations of tubercle bacilli to the tissues are lymphadenoid or visceral, the nature of the lesions depends on (I) the number and virulence of the organisms, and (2) the resistance of the host. Accordingly, in the pathogenesis of tuberculosis in any system the existence of a stage must be conceded when the lesions are minimal and sub-clinical. Having regard to such a stage in renal tuberculosis Cabot stated that when a tuberculous lesion in the kidney is closed, i.e. when it fails to communicate with the drainage system of the kidney, healing may take place under favourable conditions.

The symptoms and signs of renal tuberculosis are those of an open lesion. The clinical syndrome of renal tuberculosis is that of pyuria and frequency, with a characteristic cystoscopic picture and the characteristic pyelographic deformity of an ulcero-cavernous lesion in the kidney. Such a cavity in the parenchyma of the kidney is in direct communication with the calices through which it has ulcerated. Tubercle bacilli and pus cells are constantly present in the urine, and should be readily demonstrable in films made of the centrifuged deposit from adequate specimens of urine (Dukes, 1939). Cavity formation in the tuberculous kidney is a visceral lesion quite as gross as that in phthisis, and in order to retrace the stages in its development it occurred to Medlar (I926) to subject to serial section the kidneys removed at autopsy from patients dying from extra-urinary tuberculosis. As a result of this research it was reported that bilateral microscopic tuberculous lesions were present in the kidneys of the thirty cases examined. Medlar came to the conclusion that many of the minute scars present in his sections were due to tuberculous lesions which had healed. In I929 Harris (Table I) reported a series of cases of bone and joint tuberculosis in children in which there had been a transient tubercle bacilluria without the signs and symptoms of renal tuberculosis. He concluded that tubercle bacilluria signified the presence of a minute, sub-clinical tuberculous lesion of the kidney, and that such initial or minor renal lesions frequently healed. This statement was a direct challenge to the view long held, that tubercle bacilluria was the passage of tubercle bacilli (in a tuberculous subject) through (-I) a perfectly healthy kidney, or (2) a kidney damaged in any way, but not tuberculous, or (3) a kidney damaged by so-called tuberculous nephritis.

FIG. I.--Two minute foci of tuberculosis seen in a whole section within the circle.

FIG. 2.-Two tuberculous foci seen in Fig. I under low power.

Fig. 3.-Early tubercle follicle in epitheloid stage involving a glomerulus.

FIG. 4.-Microscopic tuberculous follicle with central caseation and giant cell formation.

FIG. 5.-Epitheloid tubercle in healing phase.

Fig. 6.- Healed tuberculous focus of tubercle in the kidney. 

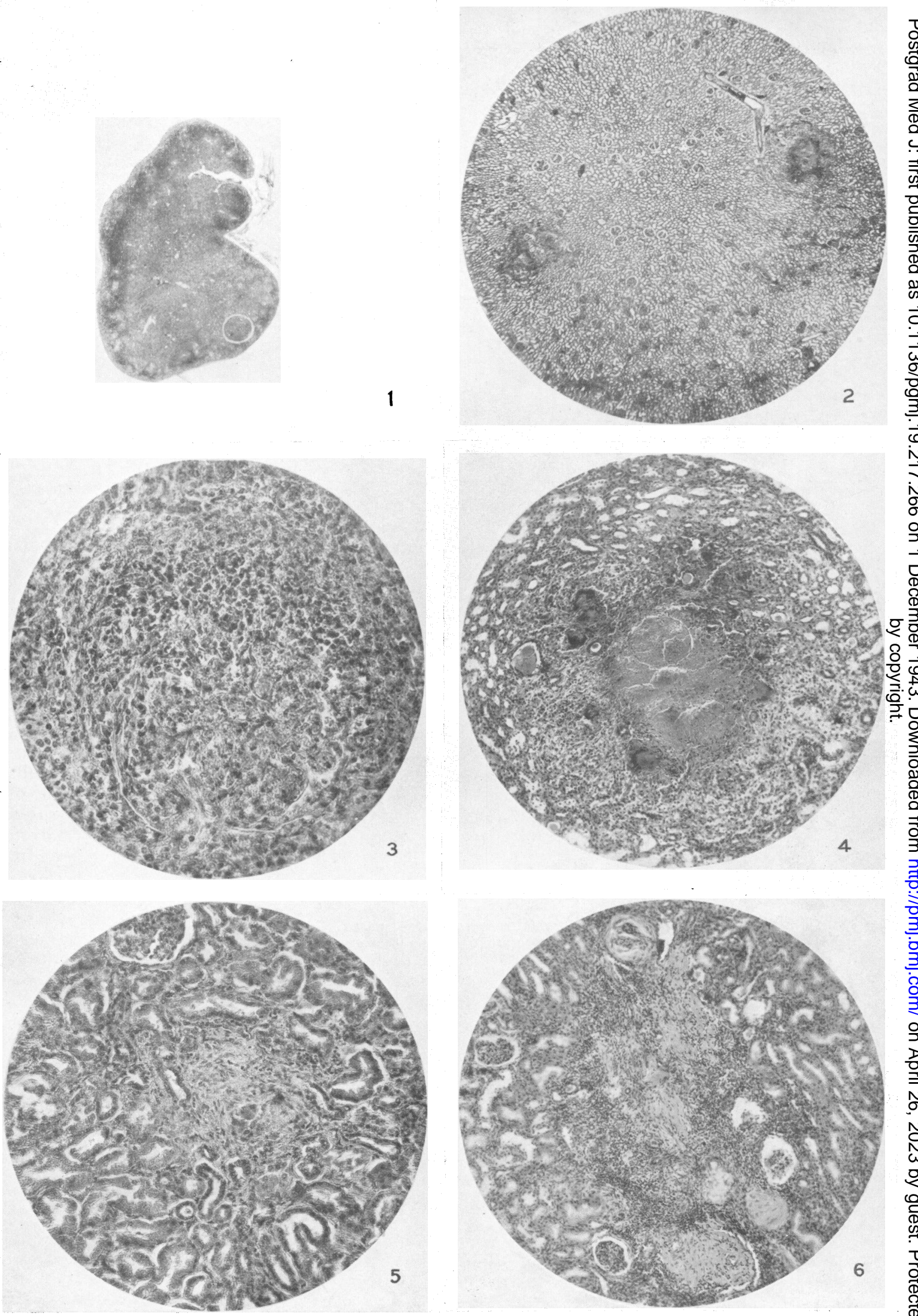


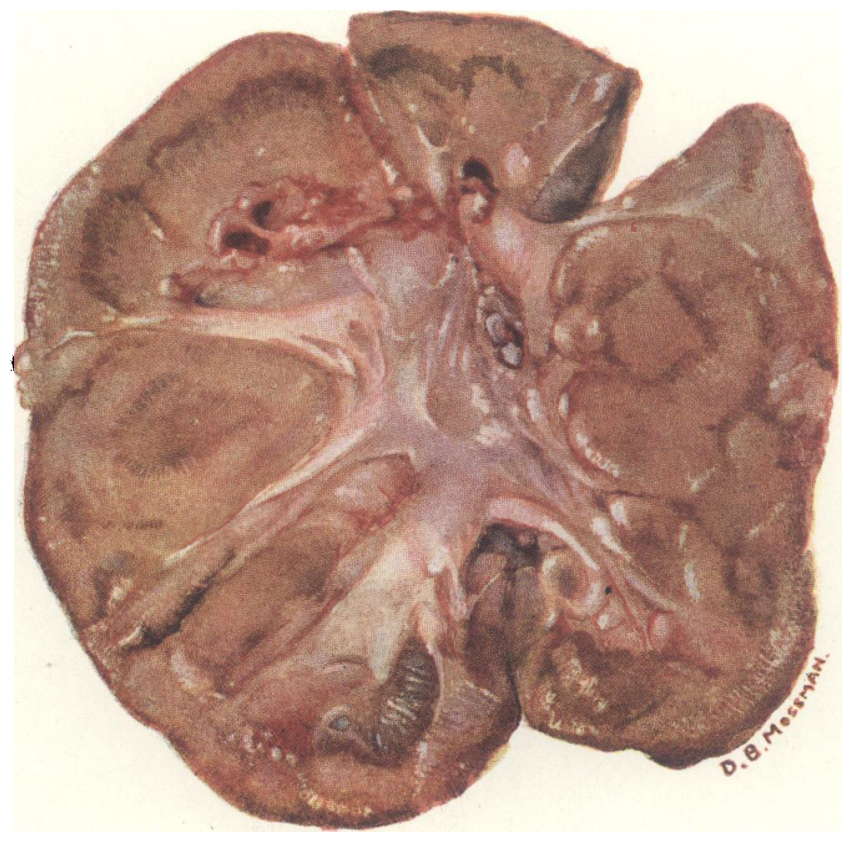

CASE Io.-Specimen removed at operation. The lesion at the upper pole caused a filling defect and distortion of the lower part of the pelvis which was not itself diseased. Compare with the pyelogram and notes on the case. 
TABLE I

RePorted Figures for Tubercle Bacilluria

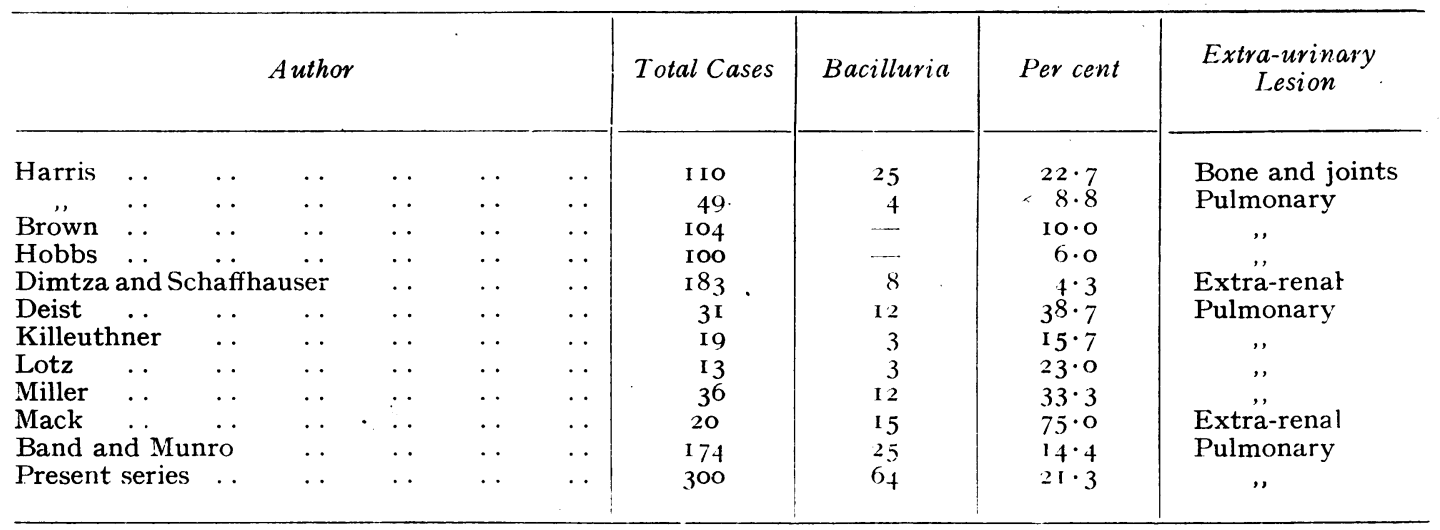

\section{Histological Studies}

Medlar's observation that microscopic renal lesions were bilateral in many sanatorium patients with no suspicion of clinical renal tuberculosis, and Harris's report of a $22 \cdot 7$ per cent incidence of tubercle bacilluria, often transient, in children with bone and joint tuberculosis were to me so suggestive, that I embarked on a long term investigation into the incidence of tubercle bacilluria in sanatorium patients who had no clinical symptoms or signs of urinary tuberculosis. Altogether three hundred cases of extra-urogenital tuberculosis were examined. My colleague, W. T. Munro, undertook the bacteriological investigation in collaboration with the late Stanley Griffiths while I carried out urological studies on the cases selected and a histological study of serial whole sections made from the kidneys of thirty patients who had died from extra-urinary tuberculosis. In the three hundred cases investigated tubercle bacilluria was found present in $2 \mathrm{I} \cdot 3$ per cent (Table II). It was significant that in this series there was a recovery rate of 23.4 per cent in which there was no recurrence of the bacilluria (Table III). On the other hand, the mortality rate was high-59 per cent (Table IV). For the histological

TABLE II

Tubercle Bacilluria. Incidence in Sexfs

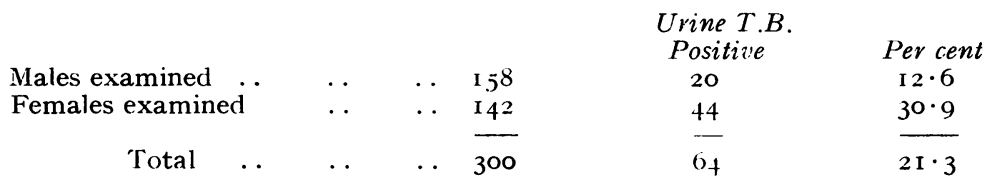

TABLE III

Tubercle Bacilluria-64 Cases Follow-up. Recovery Rate in five Years

\begin{tabular}{|c|c|c|c|c|c|c|c|}
\hline \multicolumn{6}{|c|}{ Cases } & covery & Per cent \\
\hline \multirow{2}{*}{$\begin{array}{l}\text { Males } \\
\text { Females }\end{array}$} & . & $\cdots$ & . & $\cdots$ & 20 & 5 & $25 \cdot 0$ \\
\hline & . & . & . & . & 44 & IO & $22 \cdot 7$ \\
\hline & Total & $\ldots$ & $\ldots$ & $\ldots$ & 64 & $\mathrm{I}_{5}$ & $23 \cdot 4$ \\
\hline
\end{tabular}

TABLE IV

Tubercle Bacili.uria-64 Cases Follow-up. Mortality Rate in Five Years

\begin{tabular}{llllll}
\multicolumn{2}{c}{ Cases } & & & & \\
Males & $\ldots$ & $\ldots$ & $\ldots$ & $\ldots$ & 20 \\
Females & $\ldots$ & $\ldots$ & $\ldots$ & $\ldots$ & 44 \\
& & & & & $\frac{44}{64}$
\end{tabular}

$\begin{array}{cc}\text { Deaths } & \text { Per cent } \\ \text { I } 3 & 65 \cdot 0 \\ 25 & 56 \cdot 8 \\ \frac{38}{59 \cdot 0} & \frac{5}{56}\end{array}$


study, one thousand to I,500 serial whole sections were cut from each half kidney, and every fiftieth section was stained and mounted. Such a technique provided a fairly complete scrutiny of the renal parenchyma under the microscope. It was significant that bilateral cortical foci of tuberculous disease were found in twenty-four of the twenty-seven cases of bacilluria examined. In three cases in which there had been no bacilluria in life, the kidneys were similarly examined by serial section. No tuberculous follicles were detected (Table V). The minute

TABLE V

Histological Investigation sy Serial Sections of both Kidneys from Patients who Difd FROM EXTRA-UROgENITAL TUBERCULOSIS

\begin{tabular}{|c|c|c|c|c|}
\hline & & $\begin{array}{c}\text { T.B. Renal } \\
\text { Lesions } \\
\text { Positive }\end{array}$ & $\begin{array}{l}\text { T.B. Renal } \\
\text { Lesions } \\
\text { Negative }\end{array}$ & Total \\
\hline T.B. bacilluria positive & . & . 24 & 3 & 27 \\
\hline T.B. bacilluria negative & . & $\ldots$ & 3 & 3 \\
\hline
\end{tabular}

The T.B. lesions when found were always bilateral.

lesions in the kidneys showed every stage in the development of the tubercle follicle-from the epitheloid to the larger follicle with caseation and giant cell formation. To the naked eye the lesions were only rarely visible as pin-point alterations in the staining (Figs. I and 2). They commonly arose in relation to a glomerulus (Fig. 3). or in a capillary between tubules close to a glomerulus. As the lesion progressed central caseation and surrounding giant cells became visible (Fig. 4). But in many sections follicles were studied in which a central epitheloid had become surrounded by spindle cells (Fig. 5). In others the central area had become hyalinised, and the amorphous caseous-like debris had become walled-off by organising fibrous tissue cells (Fig. 6). The follicles were healing. Elsewhere there was scar tissue only.

When autopsy examinations of the kidneys from patients who had died with a positive tubercle bacilluria have shown that microscopic bilateral cortical lesions of tubercle, in all stages of the follicle, are constantly present, and when $23 \cdot 4$ per cent of patients who have been known to have exhibited tubercle bacilluria without clinical evidence of a renal lesion make a lasting recovery, it may be concluded that: (I) the earliest tuberculous lesions in the kidney are epitheloid and mononuclear tubercles. They are situated in the cortex in relation to the glomeruli, and their presence can be detected in both kidneys: (2) the infection is blood borne; and (3) many of such minute lesions undergo spontaneous healing.

\section{Clinical Significance}

A minute tuberculous focus in the kidney, arising as it does in the glomerulus, mav have no connection with the tubules beyond that of contiguity. Such a lesion may heal and leave behind a minute scar. Under favourable circumstances, such as (a) sparse implantation of bacilli to the kidney, $(b)$ low virulence, and $(c)$ a high degree of resistance on the part of the host, certain lesions which have progressed to the stage of caseation may become walled off, or encysted, by a protective barrier of organised granulations. Neither healed lesions nor encysted foci discharge tubercle bacilli to the tubules. Encysted lesions, large or small, have no communication with the secretory and drainage system, and are hence termed "closed," and neither pus cells nor tubercle bacilli can be found in urine withdrawn from the kidney. Guinea pig inoculations are negative. With a heavier or repeated dosage of implanted tubercle bacilli, tuberculous foci in the kidney progress to the stage of caseation and infected debris discharges into neighbouring tubules. The bacilli pass down the tubular system to infect the medulla and the pyramid where contiguous follicles develop at the site of convergence of the collecting tubules. The coalescence of a number of such follicles leads to the formation of a readily visible caseating focus at the apex of the pyramid, and, later, to cavity formation with direct communication to the calices as a result of ulceration. The open lesion, cortical or medullary, with or without a demonstrable cavity on pyelography, is characterised by the presence of tubercle bacilli in the urine withdrawn from the kidney. Pus cells are constantly present in the centrifuged deposit. But whereas caseo-cavernous renal tuberculosis produces symptoms and signs of a urinary disturbance, and a characteristic pyelographic deformity can 
be obtained in addition to a positive bacteriological diagnosis, the minute cortical lesions which have been seen in the serial whole sections, are associated with no symptomatology in the urinary tract. Yet, being open lesions, there is a tubercle bacilluria, and a few pus cells are constantly present in the urine. When there is pyuria without demonstrable cause in a tuberculous subject the presence of tubercle bacilluria may not be appreciated until cultural and animal inoculation methods have been employed. These are essential if the organism is to be typed (Table VI).

TABLE VI

Types of Tubercle Bacillus in Bacilluria

$\begin{array}{cccc}\text { Human } & \text { Bovine } & \text { Total } & \text { Bovine per cent } \\ 59 & 5 & 64 & 7 \cdot 8\end{array}$

\section{Management of Cases of Tubercle Bacilluria}

Tubercle bacilluria means the presence in the kidney of minute tuberculous lesions. As the infection is blood borne, these are bilateral. The lesions may be myriad, part of a miliary dissemination. On the other hand, they may be sparsely distributed, and it has been seen that many heal, and that the tubercle bacilluria is sometimes a transient feature $(23.4$ per cent).

The number of cases which develop unilateral caseo-cavernous renal tuberculosis is small, because, in the cases reviewed, the investigations were carried out on a sanatorium population, and over 50 per cent were fatal from a generalised tuberculous dissemination. In general hospital practice, however, the mortality rate in cases exhibiting tubercle bacilluria is much less, and the incidence of the development of frank renal tuberculosis becomes higher as the progress of the more chronic type of case is followed. It must be the aim of the clinician to assist the patient to mobilise his natural resources so that additional haematogenous disseminations are prevented, and such visceral lesions as are known to be active are given an opportunity to heal. A neglectful attitude to cases of bacilluria will surely encourage an overwhelming spread of the disease, as in tuberculous broncho-pneumonia and meningitis, or a bilateral renal tuberculosis. The object of treatment is to permit such minute lesions as have been diagnosed, on the presumptive evidence of bacilluria, to heal or to reduce the renal lesions to a frank caseocavernous tuberculosis limited to one kidney, which may be extirpated at operation. To attain this, patients who present themselves with tubercle bacilluria must remain under observation until (I) the tubercle bacilluria ceases and the minute microscopic renal follicles, which have caused it, have healed or become encysted, or (2) pyelographic changes of ulcero-cavernous tuberculous have been demonstrated in one kidney when surgical intervention becomes necessary, or (3) a general dissemination and miliary tuberculosis render a fatal issue inevitable. During the period of observation the patient should have the benefit of general medical supervision under sanatorium conditions, and extra-urogenital foci should be given appropriate treatment, of which the first principle is general and local rest.

\section{REFERENCES}

I. CABOT, H., Proc, Staff Meetings, Mayo Clinic, VIII, 76 (1933).

2. MUNRO, W. T., Edinburgh Medical Journal, XLVII, II5 (I94I).

DUKES, C., Brit. Med. Jour., II, 799 (1939).

3. DUKES, C., Brit. Med. Jour., II, 799 (1939).

4. MEDLAR, Amer. Jour. Path., II, 5 (1926).

6. DIM TZA and KARTAL, Ztschr. F. Urol. Chir., XXXV, 416 (1932).

7. BAND, GRIFFITH and MUNRO, Edin. Med. Jour., XLII, 162 (1935).

8. BAND, David, Edin. Med. Jour., XLIX, 273 (I942). 